\title{
KANDUNGAN NILAI MORAL DALAM UNGKAPAN TRADISIONAL JAWA DAN PEPATAH CINA
}

\author{
Sri Harti Widyastuti \\ Fakultas Bahasa dan Seni Universitas Negeri Yogyakarta \\ email: hartiwidyastuti@yahoo.co.id
}

\begin{abstract}
Abstrak
Penelitian ini bertujuan mendeskripsikan nilai moral dalam ungkapan tradisional Jawa dan pepatah Cina. Data ungkapan Jawa bersumber dari buku pelajaran bahasa Jawa dan Kasusastran Jawi, sedangka data pepatah Cina bersumber dari buku Pepatah China Kuno untuk Generasi Modern. Kegiatan analisis dilakukan dengan penglasifikasi tema dan pembandingan ungkapan tradisional Jawa dan Cina. Temuan penelitian sebagai berikut. Pertama, klasifikasi tema yang ditemukan, yaitu (a) pengendalian diri, (b) etika berumah tangga dan bermasyarakat, (c) etika kepemimpinan, dan (d) etika berbangsa dan bernegara. Kedua, kesamaan tema menunjukkan adanya kesamaan pandangan hidup antara masyarakat Jawa dan masyarakat Cina. Kesamaan tersebut dapat menjadi media memahami budaya antara dua etnis sehingga terjadi keeratan hubungan dan saling menghormati.
\end{abstract}

Kata kunci: ungkapan Jawa, pepatah Cina, pandangan hidup, dan konfusianisme

\section{MORAL VALUES IN JAVANESE TRADITIONAL EXPRESSIONS AND CHINESE PROVERBS}

\begin{abstract}
This study aims to describe the moral values in Javanese traditional expressions and Chinese proverbs. The data on Javanese expressions were collected from Javanese course books and Kasusastran Jawi and those on Chinese proverbs were collected from Pepatah China Kuno untuk Generasi Modern. The data were analyzed by classifying the themes and comparing Javanese traditional expressions with Chinese proverbs. The findings are as follows. First, the themes include (a) self-control, (b) ethics of marriage and social life, (c) leadership ethics, and (d) ethics of managing a country and nation. Second, the similarity in themes shows a common way of life in Javanese and Chinese societies. This can serve as a means of understanding the cultures of the two ethnic groups so that there is a close relationship and mutual respect.
\end{abstract}

Keywords: Javanese expressions, Chinese proverbs, way of life, and Confucianism

\section{PENDAHULUAN}

Masyarakat Jawa mempunyai tradisi yang merupakan konstalisasi dari kearifan lokal yang diturunkan dari pandangan hidupnya. Pandangan hidup masyarakat Jawa yang merupakan akar budaya menyesuaikan dengan sejarah bangsa Jawa. Dalam sejarahnya, orang Jawa dianggap keturunan orang-orang Melayu. Nenek moyang orang Jawa mempunyai latar belakang jiwa estetika yang tinggi, demikian pula nenek moyang bangsa Jawa merupakan bangsa yang cerdas, terbukti pada dinamika kerajaan-kerajaan Jawa Tengah pertama yang menghasilkan salah satu artefak keajaiban dunia yaitu candi Borobudur serta candi Prambanan. Pada masa kerajaan Jawa Timur dan Majapahit, tampak kecerdasan yang sangat tinggi yang dimiliki oleh bangsa Jawa karena 
dapat mengembangkan kekuasaan dan mempersatukan wilayah Nusantara, melebihi wilayah Indonesia sekarang ini.

Bangsa Cina masuk ke Jawa sudah dimulai dari tiga ribu tahun sebelum Masehi (3000 SM) yang merupakan gelombang pertama imigran Melayu yang berasal dari Cina Selatan (Magnis Suseno, 1996:21). Pada abad VII di Jawa sudah terdapat laporan-laporan bangsa Cina yang tinggal di Jawa. Semula orang-orang Cina digambarkan hidup berkelompok dengan kondisi ekonomi yang tidak memadai, bahkan, pada abad XVII, di Batavia muncul daerah yang disebut sebagai kampong China (Stockdale, 2010:47). Pada tahun 1740 terjadi pemberontakan Cina yang disebabkan oleh semakin banyaknya orang Cina yang datang ke Batavia, sehingga merisaukan Kompeni. Selanjutnya, Kompeni menyusun politik untuk mengusir bangsa Cina sehingga terjadi pemberontakan. Ribuan orang Cina melarikan diri ke luar kota dan ke pedalaman (Stockdale, 2010:47).

Sebagai bangsa pendatang, orang Cina mempunyai kekuatan budaya yang mampu mempersatukan bangsa tersebut. Disamping itu, kekuatan tradisi yang berawal dari munculnya pandangan hidup agar kuat, sukses, tahan uji di Jawa muncul dan mengokohkan jati diri bangsa Cina tersebut. Dalam keseharian kehidupannya, sampai saat ini orang Cina selalu merabuk budaya dengan cara mereka tetap mengajarkan nilai-nilai budaya lokal dan bahasa ibu, bahasa Cina. Oleh karena itu, sampai saat ini bangsa Cina di Indonesia menjadi bangsa yang kental dan kokoh persatuannya, bahkan menjadi kunci kemajuan ekonomi negara Indonesia.

Berdasarkan latar belakang kondisi masyarakat Jawa dan Cina tersebut, maka dapat disebutkan bahwa bangsa Jawa adalah bangsa yang tua, yang tradisinya hampir sama dengan tradisi Cina. Namun demikian, antara Jawa dan Cina kadang ada perbedaan karakter yang muncul dari sejarah kedua bangsa tersebut. Disebabkan oleh perbedaan tersebut, maka etnis Jawa dan Cina kadang mempunyai jurang pemisah dalam berhubungan. Kecemburuan orang Jawa sebagai pemilik lahan terhadap orang Cina yang hanya sebagai pendatang bisa memperuncing keadaan.

Oleh karena itu, penelitian ini mencoba menyandingkan dan membandingkan nilai-nilai moral yang terdapat pada ungkapan tradisional Jawa dengan pepatah Cina. Diharapkan, pemaknaan terhadap kedua tradisi tersebut dapat memperbaiki hubungan antar etnis tersebut.

Ungkapan tradisional merupakan bagian dari kearifan lokal. Oleh karena itu, ungkapan tradisional dimiliki oleh suku-suku bangsa dalam lingkungan etnis tertentu. Misalnya, suku Jawa yang terkenal dengan nama ungkapan tradisional Jawa paribasan, bebasan, saloka, dan wangsalan. Di samping itu, dikenal pula bentuk cangkriman, parikan, pepindhan, sanepa, panyandra dan isbat (Subalidinata, 1981:63-85). Di Bali terdapat paribasan yang meliputi sesonggan (pepatah), sesenggakan (ibarat), wewangsalan (tamsit), sloka (bidal), bebladbadan (metafora), peparikan (pantun atau madali), pepindan (perumpamaan), sesawangan (perumpamaan), ucanglutan (olol-olok), raos ngempelin (kata-kata mendua arti atau pelawak), sesimbing (sindiran), sesemon (sindiran halus), sipta (alamat atau pertanda), sesapan (doa), gigihan (bahasa spontan, bahasa jumbuh atau bahasa kesombongan individu ketika ingin mengungkapkan kebanggaan diri) (Suarta, 2012:2). Sementara di Sunda, ungkapan tradisional dikenal dengan paribasan. Berdasarkan fenomena bahwa ungkapan tradisional tersebut ada pada etnis budaya masyarakat, maka dapat disebutkan bahwa ungkapan tradisional tersebut bersifat universal.

Ungkapan tradisional pada etnis Cina juga merupakan sesuatu yang sangat digemari dan merupakan hasil tradisinya. 
Menurut Confuceis, seseorang dapat mengetahui hal-hal baru dengan meninjau hal-hal yang lama. Hal itu berarti untuk mengetahui hal-hal yang baru seseorang harus meninjau hal-hal yang lama (Wang Keping, 2011:1). Ungkapan tradisional bagi masyarakat Cina dipandang sebagai salah satu cara untuk mendapatkan keseimbangan. Dalam istilah konfusianisme terjadi keseimbangan jalan surgawi dan jalan manusia (Wang Keping, 2011:15).

Konfusianisme adalah kemanusiaan, suatu filsafat atau sikap yang berhubungan dengan kemanusiaan, tujuan dan keinginannya, daripada sesuatu yang bersifat abstrak dan masalah teologi (http://members.fortunecity.com). Lebih lanjut diungkapkan oleh Annesya (http:// frenndw.wordpress.com), menyatakan bahwa konfusianisme adalah warisan dari timur, suatu bentuk budaya yang menekankan pada kehidupan keluarga dan perkembangan pribadi. Budaya konfusianisme merupakan dasar yang unik dari tingkah laku atau sikap masyarakat di Asia Timur.

Pada dasarnya, konfusianisme mempunyai pokok-pokok ajaran. Pertama, setiap manusia memiliki yen, artinya setiap manusia memiliki keluhuran budi, cerita dan kemanusiaan dalam dunianya. Orang yang telah memiliki yen senantiasa akan bersedia mengorbankan dirinya untuk menjaga keseimbangan dirinya dengan orang lain. Kedua, setiap manusia harus menjaga keseimbangan, yaitu menjaga lima hubungan timbal balik sebagai suatu lingkaran keseimbangan hidup yaitu hubungan yang seimbang. Kelima bentuk hubungan tersebut yaitu, (a) hubungan antara ayah dan anak, (b) hubungan antara saudara tua dan saudara muda, (c) hubungan antara suami dan istri, (d) hubungan antara hawa yang lebih tua dan yang lebih muda umurnya, dan (e) hubungan antara raja dan rakyat. Sementara itu, masyarakat Jawa mempunyai pandangan hidup yang terwadahi dalam ungkapan tradisional seperti diuraikan di atas.

\section{METODE}

Penelitian ini menggunakan pendekatan deskriptif untuk mendeskripsikan hasil analisis data yang diambil dari ungkapan tradisional yang terdapat dan tersebar di buku-buku pelajaran bahasa Jawa untuk tingkat Sekolah Dasar (SD), Sekolah Menengah Pertama (SMP), dan Sekolah Menengah Atas (SMA), serta dalam buku Kasusastran Jawi.

Teknik pengumpulan data yang digunakan adalah teknik baca dan catat. Kegiatan baca dilakukan secara berulangulang, kemudian dilakukan analisis secara berulang sampai ditemukan kategori. Untuk itu, diperlukan keabsahan data untuk instrumen penelitian.

Keabsahan data menggunakan uji validitas dan reliabilitas. Uji validitas menggunakan uji validitas semantis, yaitu mencermati, mengamati secara berulang ungkapan-ungkapan tradisional untuk kemudian diambil maknanya. Reliabilitas data menggunakan pembacaan dan pemahaman secara berulang menyesuaikan dengan konteks.

\section{HASIL DAN PEMBAHASAN Tema Ungkapan Tradisional Jawa dan Pepatah Cina}

Berdasarkan penelitian yang dilakukan terhadap ungkapan tradisional Jawa dan pepatah Cina, maka terdapat kesamaan tema. Namun demikian, terdapat tema yang sering tidak ditemukan dalam pepatah Cina, yaitu etika berbangsa dan bernegara.

Disamping itu, terdapat ungkapan tradisional Jawa dan Cina yang mempunyai persamaan. Persamaan tersebut menunjukkan adanya persamaan pandangan masyarakat pendukungnya terhadap kehidupan. Disebut demikian karena ungkapan tradisional melambangkan pandangan hidup masyarakat pendukungnya. Pada ungkapan tradisional Becik ketitik ala ketara, wani ngalah dhuwur wekasane mengandung makna bahwa orang 
harus dapat mengendalikan diri karena bagaimanapun perbuatan buruk pada suatu ketika akan terbuka, dan orang yang berani mengalah akan dapat keunggulan. Tema pengendalian diri dirumuskan dari ungkapan tradisional yang mempunyai makna untuk pengendalian nafsu, keinginan, dan hal-hal yang mengakibatkan perilaku buruk.

Tema etika berumah tangga dan bermasyarakat diturunkan dari ungkapan tradisional yang bermakna ajakan atau larangan agar dalam berhubungan dengan orang lain maupun anggota keluarga berjalan seimbang dan harmoni.

Ungkapan tradisional tersebut sebagian juga mengandung tema bagaimana memimpin dengan baik. Disamping itu, agar kepemimpinannya menimbulkan ketenangan bagi masyarakat yang dipimpinnya.

Disebabkan oleh perbedaan tersebut, maka etnis Jawa dan Cina kadang mempunyai jurang pemisah dalam berhubungan. Kecemburuan orang Jawa sebagai pemilik lahan terhadap orang Cina yang hanya sebagai pendatang bisa memperuncing keadaan.

Oleh karena itu, penelitian ini mencoba menyandingkan dan membandingkan nilai-nilai moral budi pekerti antara bangsa Jawa dan konfusianisme Cina. Diharapkan pemaknaan terhadap kedua tradisi tersebut dapat memperbaiki hubungan antar etnis tersebut.

\section{Pandangan Hidup Masyarakat Jawa dan Cina}

Berdasarkan deskripsi wujud ungkapan tradisional Jawa maupun Cina yang telah didapat, tampak bahwa tema pengendalian diri berupa nasehat agar orang tidak sombong, sadar bahwa hidup memerlukan proses, tidak bersifat instan, kadang di atas kadang di bawah, tidak boleh berbuat jahat dan seterusnya. Tema etika berumah tangga dan hidup bermasyarakat juga sangat banyak. Ba- gaimana menjadi seorang laki-laki yang disegani, tanggung jawab sebagai orang tua, pentingnya nasehat untuk orang yang lebih muda, sindiran dan nasehat agar anak muda menghormati orang tuanya dan seterusnya. Di samping tema-tema tersebut terdapat tema etika kepemimpinan, yaitu nasehat terhadap para pemimpin di level apapun. Tema etika bernegara dan berbangsa yang dapat ditafsirkan bagaimana konsep manusia Jawa dalam memandang cara berbangsa dan bernegara.

Hasil telaah perbandingan menunjukkan bahwa ungkapan becik ketitik ala ketara mempunyai makna yang hampir sama dengan Tian xing jian zi yi zi qiang bu xi di shi kun jun zi yi hou de zai wu. Hal itu menyiratkan bahwa terdapat pandangan hidup masyarakat Jawa yang sama dengan pandangan hidup masyarakat Cina tentang perlunya pengendalian diri karena bagaimanapun orang yang berbuat buruk pada suatu ketika tetap akan terbongkar. Keburukan akan terbongkar dan akan terlihat siapa yang benar dan berbuat baik. Oleh karena itu, orang harus tetap konsisten untuk berbuat baik.

Sementara itu kebaikan, budi luhur (yi nou de) dan integritas tinggi (zai wu) merupakan kekuatan kehidupan. Oleh karena itu, pengendalian diri agar tidak berbuat buruk dan selalu berbuat baik merupakan hal yang sangat diperhatikan masyarakat Cina. Pengendalian diri menjadi pangkal pandangan kehidupan dalam masyarakat Jawa. Untuk tercapainya harmoni merupakan kaidah dasar kehidupan masyarakat Jawa (Magnis Suseno, 1996:38).

Dari perbandingan kedua ungkapan tersebut, maka tampak bahwa bangsa Jawa dan Cina sesungguhnya mempunyai pandangan budaya yang sama. Adanya prinsip kerukunan maka masyarakat Indonesia bisa lebih mudah untuk bekerjasama dengan masyarakat Cina tanpa takut terjadi manipulasi. 
Ungkapan tradisional masyarakatJawa yang berbunyi Cakra manggilingan, ungkapan tersebut merupakan sikap manusia Jawa terhadap kehidupan yang kadang di atas kadang di bawah, kadang duduk sebagai pejabat tinggi yang baik, kadang menjadi rakyat yang mempunyai keterbatasan. Ungkapan tradisional cakra manggilingan menjadi dasar tindak manusia dan pandangan hidup masyarakat Jawa. Ungkapan tersebut bermakna hidup tidak selamanya ada di atas atau menjadi pejabat, dengan kondisi segala sesuatunya serba ada, suatu ketika ia akan turun, bahkan akan mengalami saat-saat yang sulit pula. Menurut tasawuf, hidup adalah perjalanan, untuk itu diperlukan roda kehidupan. Oleh karena itu dalam perputarannya tidak perlu berebutan dan bersaing.

Pandangan tersebut seperti yang terdapat pada pepatah Cina Shang shan ruo shui shan li wan wu er bu zheng yang mengibaratkan hidup seperti gerak air, mengalir kadang melewati batu-batu, kadang lancar. Namun demikian, air tidak pernah berebut dan bersaing, ia konsisten pada alurnya. Pandangan tersebut merupakan pandangan masyarakat Cina yang mengandung makna pengendalian diri, untuk hidup rukun sehingga tercapai tertib kosmos.

Hati-hati, teliti, dan tekun merupakan pandangan umum masyarakat Jawa dan Cina. Masyarakat Jawa memandang bahwa pekerjaan yang dilakukan dengan terburu-buru, tergesa-gesa, tanpa dipikir dan dipertimbangkan masak-masak pasti hasilnya tidak maksimal dan berpotensi menimbulkan masalah.

Masyarakat Cina justru menganggap bahwa mengerjakan sesuatu secara terburu-buru justru tidak ada gunanya. Pandangan hidup yang demikian menandakan bahwa sesungguhnya masyarakat Jawa dan Cina menomor satukan kualitas dalam perilaku hidup dan karyanya. Kesabaran, kejujuran, dan ketekunan men- jadi hal yang utama bagi orang Jawa yang ingin menjadi orang sukses. Hal demikian juga terdapat pada pepatah Cina Yu su ze bu da.

Menurut pepatah Jawa sing sapa temen tinemu yaitu siapa yang sabar, jujur, dan tekun akan mendapatkan hasil. Dalam ungkapan Cina Taoli buy an xia zi cheng $x i$, walaupun buah persik dan buah plum tak dapat berbicara namun dengan ketekunan, ketelitian, dan kesabaran jalan terang akan dapat dicapai setelah menapaki jalan yang terlihat dibawah buah-buahan tersebut. Oleh karena itu model instan atau segala sesuatu dicapai dengan cepat tanpa proses bukan perilaku yang baik bagi masyarakat Jawa maupun Cina.

Hukum karma adalah kepercayaan masyarakat Hindu yang kemudian masuk dalam karya-karya sastra Jawa pada masa Jawa Kuna, Tengahan, dan Pra Islam. Pandangan hidup tersebut bersifat universal. Oleh karena itu, ungkapan ngundhuh wohing pakarti merupakan pepatah yang relevan sepanjang masa. Adapun makna ungkapan tersebut adalah orang akan mendapat pahala ataupun hukuman dari Tuhan sesuai dengan tindakannya. Sementara pepatah Cina Ai ren zhe ren bi cong er ai zhi li ren zhe ren bi chong er li zhi wu ren zhe ren bi cong er wu zhi hai ren zhe ren bi cong er hai zhi dan Tian wang hui hui shu er bu shi mengatakan bahwa siapa yang mencinta seseorang tentu akan dicintai, demikian pula orang yang memanfaatkan orang lain akan dimanfaatkan juga oleh orang lain, orang yang membenci orang lain akan dibenci pula oleh orang lain, demikian pula orang yang melukai orang lain akan dilukai oleh orang lain pula. Kedua pepatah tersebut sangat mirip. Oleh karena itu dapat dikatakan bahwa pandangan hidup Jawa dan Cina tentang hukum karma adalah sama.

Eling waspada merupakan ungkapan tradisional yang sangat terkenal bagi masyarakat Jawa. Ungkapan tersebut berfungsi sebagai pengendalian agar hidup 
tetap harmonis, tentram, dan damai. Ungkapan tersebut juga selaras dengan ungkapan Cina yang berbunyi an er bu wang wei cun er bu wang wang zhi er bu wang luan.

Citra laki-laki ideal juga disampaikan dalam wujud pepatah Jawa yang berbunyi perabotaning wong lanang inggih menika bares, mantep, lan wani, artinya laki-laki sejati adalah laki-laki yang mempunyai sikap jujur, teguh hati, dan bersikap berani. Dalam pepatah Cina San lun ke duo shuai ye pifu bu ke duo zhi ye, pepatah tersebut disampaikan yang mengatakan bahwa hidup harus hati-hati dan waspada.

Hati-hati dalam memilih teman cukup tinggi bagi masyarakat Jawa karena lingkungan sangat mempengaruhi perilaku orang, walaupun orang tersebut pada dasarnya baik namun bila berhubungan terus dengan orang yang buruk kelakuannya maka orang tersebut akan dapat berubah menjadiburuk. Dalam masyarakat Jawa sering disebut sebagai cedhak kebo gupak. Pepatah tersebut hamper sama dengan pepatah Cina San ren xing bi you wo shi yan ze qi shan zhe er cong zhi qi bu shan zhe er gai zhi.

Ungkapan tradisional kebo nusu gudel bagi masyarakat Jawa bisa berarti orang tua mengikuti kemauan anaknya, seperti halnya ungkapan tradisional yang berbunyi tut wuri handayani. Namun demikian, ungkapan tersebut bisa pula berarti murid tidak selalu lebih rendah dari guru seperti pepatah Cina Di zi bu bi bur u shi shi bu bi xian yu di zi.

Ungkapan tradisional yang menyiratkan kedudukan orang tua sebagai penanggung jawab semua tindakan dan perilaku anaknya. Namun demikian, peran tersebut sangat dihayati oleh orang tua masyarakat Jawa yang terdapat pada ungkapan anak polah bapa kepradah. Ungkapan tradisional tersebut sesuai dengan pepatah Cina yang berbunyi Fu mu zhi xin ren jie you zhi.

Dalam kehidupan masyarakat Jawa terdapat ungkapan tradisional yang ber- fungsi untuk memperingatkan kepada masyarakat bahwa tingkah laku dan kebiasaan orang pasti tidak lepas dari tingkah laku dan kebiasaan orang tuanya, yang dingkapkan melalui unkapan tradisional kacang ora ninggal lanjaran. Pandangan tersebut sesuai dengan pepatah Cina $\mathrm{Fu}$ ci er jiao zi xiao er zhen xiong ai er you di jing er shun Peringatan agar masyarakat hatihati terhadap penampilan dan tutur kata orang, karena penampilan tidak relevan dengan tindakan yang dilakukan seperti pada pepatah Cina Ta po tie xie wu mi chu de lai quan bu fei gong fu.

Dalam ungkapan traditional dideskripsikan sebagai nyolong pethek, peringatan masyarakat Jawa terhadap hal ini cukup kuat, terbukti dengan terdapatnya ceritacerita yang memuat pesan moral, seperti misalnya cerita tentang burung bangau yang karena kehabisan akal untuk mencari makan kemudian berpura pura menjadi sangat baik penampilan burung bangau yang terlihat seperti sosok bijaksana, elegan, membuat ikan-ikan hilang kewaspadaannya kemudian tertipu. Akibatnya banyak ikan mati karena terjerumus dengan tipuan yang dilakukan oleh burung bangau. Cerita ini terdapat pada cerita berbingkai Tantri Kamandaka dan Suluk Wujil.

Dalam masyarakat Jawa konsistensi juga menjadi hal yang diperhitungkan dalam kehidupan supaya tercapai kerukunan. Hal itu tampak pada ungkapan $i$ du didilat maneh. Dalam masyarakat Jawa, seorang pemimpin tidak boleh bermain dengan janji, harus tetap konsisten, karena pemimpin harus sabda pandhita ratu. Masyarakat Cina juga mempunyai pandangan hidup yang sama. Hal itu tampak pada ungkapan tradisional yang berbunyi yi yan chu kou si manan zhui, yang berarti kata yang sudah terucap tidak mungkin ditarik kembali.

Menurut Suseno (1996: 10-256) bahwa pada prinsipnya orang Jawa mempunyai sikap dan pandangan hidup hormat dan rukun semua perilaku diarahkan pada ter- 
ciptanya keadaan rukun dan hormat sehingga semua berjalan aman dan tenang tercipta ketertiban dunia.

\section{SIMPULAN}

Dari analisis penelitian di atas, maka tampak bahwa terdapat ungkapan tradisional Jawa yang mengandung pandangan hidup masyarakat Jawa. Pandangan hidup tersebut mengait dengan prinsip hidup rukun dan hormat yang kesemuanya dalam rangka menciptakan ketertiban mikrokosmos dan makrokosmos. Prinsipprinsip tersebut tercermin pada tema atau makna ungkapan tradisional Jawa tentang pengendalian diri, etika berumah tangga dan bermasyarakat, etika kepemimpinan, etika berbangsa dan bernegara.

Tema-tema dalam ungkapan tradisional Jawa tersebut juga terdapat pada pepatah Cina. Setelah diperbandingkan, terdapat persamaan ungkapan tradisional Jawa dengan pepatah Cina yang menunjukkan adanya kesamaan pandangan hidup antara masyarakat Cina dengan masyarakat Jawa. Adanya kesamaan tersebut menjadikan peluang untuk saling memahami budaya antara dua etnis tersebut, sehingga akan terjadi keeratan hubungan atau hubungan yang erat dan saling menghormati antara dua bangsa.

\section{UCAPAN TERIMA KASIH}

Ucapan terima kasih disampaikan kepada Koordinator Badan Pertimbangan Penelitian FBS UNY yang telah memberikan kesempatan dan biaya untuk melakukan penelitian yang kemudian ditulis dalam artikel ini. Selain itu, terima kasih disampaikan pula kepada tim redaksi majalah Litera yang telah memberikan masukan untuk perbaikan artikel ini.

\section{DAFTAR PUSTAKA}

Amrih, Pitoyo. 2008. Ilmu Kearifan Jawa. Yogyakarta: Pinus Book Publisher.

Dwi Lestari, Endang. 2009. Kawruh Sapala Basa. Klaten: PT. Intan Pariwara.

Jatmikoningtyas, Yuniati. (Tanpa Tahun). Pepak Basa Jawi Anyar. Solo: CV. Bringin 55.

Keping, Wang. 2011. Etos Budaya China. Jakarta: Kompas Gramedia.

Magnis Suseno, Franz. 1996. Etika Jawa: Sebuah Analisa Falsafi tentang Kebijaksanaan Hidup Jawa. Jakarta: PT Gramedia Pustaka Utama.

Mu Zi. 2011. Pepatah China Kuno untuk Generasi Modern. Jakarta: PT Elex Media Komputindo.

Santoso, Imam Budi. 2010. Nguri-uri Paribasan Jawi. Klaten: PT Intan Pariwara.

Stockdale, John Joseph. 2010. Eksotisme Jawa. Yogyakarta: Progresiv Book.

Suarta, I Made. 2012. Membangun Pendidikan yang Berkarakter Kearifan Lokal dalam Kearifan Lokal dan Pendidikan Karakter. Denpasar Bali: Buku Proseding Konferensi Internasional Budaya Daerah ke-II.

Subalidinata. 1981. Kasusastran Jawa. Yogyakarta: Universitas Gadjah Mada.

Subroto, Suryo, dkk. (Tanpa Tahun). Mumpuni Basa Jawi Pepak. Surabaya: CV. Pustaka Agung Harapan.

Tofani, M. Abi, dkk. (Tanpa Tahun). Tatanan Anyar Pinter Basa Jawi Pepak. Surabaya: Pustaka Agung Harapan. 


\section{Lampiran 1 Contoh Ungkapan Tradisional Jawa}

\begin{tabular}{|c|c|c|c|}
\hline NO & UNGKAPAN & MAKNA & TEMA \\
\hline 1 & $\begin{array}{l}\text { Adhang-adhang } \\
\text { tetese embun }\end{array}$ & $\begin{array}{l}\text { Mengharapkan sesuatu yang belum tentu } \\
\text { hasilnya. }\end{array}$ & \\
\hline 2 & Aji godhong garing & Tidak berharga/ rendah sekali & \\
\hline 3 & Anggenthong umos & Orang yang tidak bisa menyimpan rahasia & \\
\hline 4 & Angon mangsa & $\begin{array}{l}\text { Mencari waktu yang baik untuk melakukan suatu } \\
\text { perbuatan }\end{array}$ & \\
\hline 5 & $\begin{array}{l}\text { Becik ketitik ala } \\
\text { ketara }\end{array}$ & Yang baik kelihatan yang buruk pun kelihatan & Pengendalian \\
\hline 6 & Belo melu seton & Hanya ikut-ikutan tanpa tahu maksud tujuannya & diri \\
\hline 7 & $\begin{array}{l}\text { Beras wutah arang } \\
\text { bali menyang takere }\end{array}$ & $\begin{array}{l}\text { Sesuatu yang sudah berubah tidak akan kembali } \\
\text { seperti semula }\end{array}$ & \\
\hline 8 & $\begin{array}{l}\text { Mburu uceng } \\
\text { kelangan deleg }\end{array}$ & $\begin{array}{l}\text { Mengejar hal kecil namun mengorbankan hal } \\
\text { yang besar/ penting }\end{array}$ & \\
\hline 9 & Carang canthel & Tidak diajak diskusi namun ikut berbicara & \\
\hline 10 & $\begin{array}{l}\text { Car-cor kaya kurang } \\
\text { janganan }\end{array}$ & Berbicara asal bunyi tanpa dipikir dahulu & \\
\hline 11 & $\begin{array}{l}\text { Kacang ora ninggal } \\
\text { lanjaran }\end{array}$ & $\begin{array}{l}\text { Seorang anak biasanya akan meniru perilaku } \\
\text { kedua orang tuanya, anak buah meniru bosnya } \\
\text { dalam mengambil kebijakan }\end{array}$ & \\
\hline 12 & Kadang konang & Mau mengaku saudara hanya yang kaya saja & \\
\hline 13 & $\begin{array}{l}\text { Mikul dhuwur } \\
\text { mendhem jero }\end{array}$ & $\begin{array}{l}\text { Mengubur dalam keburukan dan kekurangan } \\
\text { orang tua, aib keluarga, dan kelemahan } \\
\text { masyarakat serta dapat menjunjung martabat } \\
\text { keluarga, selalu berbuat mulia untuk menjaga } \\
\text { nama baik orang tua }\end{array}$ & \\
\hline 14 & Bobot bibit bebet & $\begin{array}{l}\text { Melihat, mempertimbangkan kepandaian, } \\
\text { keturunan dan kekayaan dalam hal memilih } \\
\text { pasangan hidup }\end{array}$ & \\
\hline 15 & $\begin{array}{l}\text { Ilang-ilangan } \\
\text { endhog siji }\end{array}$ & Bernekad kehilangan satu anak tidak masalah & $\begin{array}{c}\text { tangga dan } \\
\text { bermasyarakat }\end{array}$ \\
\hline 16 & $\begin{array}{l}\text { Anak polah bapa } \\
\text { kepradah }\end{array}$ & $\begin{array}{l}\text { Perbuatan anak juga akan ditanggung oleh orang } \\
\text { tuanya }\end{array}$ & \\
\hline 17 & Kebo nusu gudel & Orang tua mengikuti kemauan anaknya & \\
\hline 18 & $\begin{array}{l}\text { Kegedhen empyak } \\
\text { kurang cagak }\end{array}$ & $\begin{array}{l}\text { Kebesaran atap kurang tiang, ibarat utuk orang } \\
\text { yang besar pengeluarannya daripada } \\
\text { pemasukannya. }\end{array}$ & \\
\hline 19 & $\begin{array}{l}\text { Milih-milih tebu } \\
\text { oleh oreg }\end{array}$ & $\begin{array}{l}\text { Memilih hal yang baik namun justru dapat yang } \\
\text { jelek }\end{array}$ & \\
\hline 20 & $\begin{array}{l}\text { Ora ana banyu mili } \\
\text { mendhuwur }\end{array}$ & Tidak ada masalah tanpa sebab & \\
\hline 21 & Marangkani kudhi & $\begin{array}{l}\text { Siap untuk bernegosiasi dengan orang yang sulit, } \\
\text { siap berdiplomasi dengan tokoh keras, siap } \\
\text { mengatasi segala kemungkinan }\end{array}$ & \\
\hline 22 & $\begin{array}{l}\text { Memayu hayuning } \\
\text { bawana }\end{array}$ & $\begin{array}{l}\text { Upaya melestarikan dan menjaga bumi/ } \\
\text { lingkungan }\end{array}$ & \\
\hline
\end{tabular}

LITERA, Volume 11, Nomor 1, April 2012 
23 Catur darmaning Empat sifat utama dari seorang pemimpin sebagai raja

panglima militer yaitu jana wisesa, menguasai segala macam ilmu pengetahuan baik teknologi, kemiliteran, ilmu pengetahuan agama, kaprabitaning praja, mempunyai belas kasihan kepada bawahan, kawiryan, panglima harus mempunyai keberanian untuk menegakkan kebenaran dan keadilan, kawibawan, memiliki kewibawaan terhadap rakyat sehingga setiap perintahnya dapat dilaksanakan

24 Agama ageming aji Agama busana yang berharga. Agama itu pegangan utama dalam hidup

25 Songsong gilap Wewenang atau kepemimpinan yang bersumber payung agung dari pulung atau wahyu itulah yang menyebabkan kepemimpinan berubah menjadi magis, wingit, angker, gaib, dan serba supranatural

26 Aja dumeh aja Jangan sok, jangan mudah terkagum-kagum, gumunan aja jangan mudah terkejut. Prinsip hidup agar tidak kagetan sombong, tidak mudah terkagum terhadap suatu hal yang baru, karena akan mudah terperdaya

27 Ambeg adil Penuh rasa keadilan dan bijaksana paramarta

28 Ing madya mangun karsa

Di tengah-tengah membangun kehendak, pemimpin hendaknya bisa menjadi penyatu tujuan dan cita-cita masyarakat

29 Ing ngarsa sung tuladha

30 Bawa leksana

Di depan memberi contoh, teladan. Pemimpin bisa memberikan panutan-panutan yang baik

Kendalikan nafsumu. Seseorang harus mampu mengendalikan nafsu dirinya.

31 Negara mawa tata Masing-masing daerah mempunyai adat-istiadat desa mawa cara sendiri yang berbeda

32 Kenthung kriyung Masyarakat desa merupakan satu-kesatuan cakiker asu gathik lengkap dengan peraturan-peraturan dan adatistiadat yang harus dipatuhi oleh setiap anggota. Dengan demikian kesadaran hukum masyarakat desa cukup tinggi.

33 Aja nggege mangsa Jangan mengharap yang belum waktunya, mengharap sesuatu yang sulit terjadi

34 Srengenge pine Raja patih dan jaksa pada saat menghadiri suatu banyu kinum bumi perkara, pemeriksaannya harus jelas seperti pinendhem terangnya matahari, putusannya adil seperti tegaknya air dalam gelas, tutur katanya lemah lembut pertanda berbudi dan tidak menghina orang yang diadili

35 Gemah ripah loh Ramai pelabuhan dan perdagangannya, murah jinawi sandang pangannya, subur makmur.

36 Murah kang sarwa Tertata tenteram, makmur, dan aman. tinuku, thukul kang 
sarwa tinandur, tata tentrem kerta raharja

37 Sayuk rukun saiyeg Manunggal rukun bersama-sama satu tujuan. saeka praya

38 Rukun agawe Kerukunan akan membuat kedamaian, rukun itu santoso akan menjauhkan dari pertengkaran

\section{Lampiran 2 Ungkapan Tradisional Cina}

\begin{tabular}{|c|c|c|c|}
\hline NO & PEPETAH CINA & MAKNA & TEMA \\
\hline 1 & $\begin{array}{l}\text { Tian xing jian zi yi zi } \\
\text { qiang bu xi di shi kun } \\
\text { jun zi yi hou de zai wu }\end{array}$ & $\begin{array}{l}\text { Tuhan memiliki yang teramat kuat, sehingga } \\
\text { orang yang berbudi luhur menjadikan diri } \\
\text { mereka sangat kuat dan tak mengenal lelah. } \\
\text { Sementara bumi memiliki kekuatan yang } \\
\text { bersifat pasif sehingga orang yang berbudi } \\
\text { luhur dan berintegritas tinggi akan mampu } \\
\text { bertahan dari dunia luar }\end{array}$ & $\begin{array}{l}\text { Pengendalian } \\
\text { diri }\end{array}$ \\
\hline 2 & $\begin{array}{l}\text { Shang shan ruo shui } \\
\text { shan li wan wu er bu } \\
\text { zheng }\end{array}$ & $\begin{array}{l}\text { Kebajikan dengan nilai tertinggi menyerupai } \\
\text { gerakan air, yaitu member untuk semua } \\
\text { tetapi tak pernah merebut atau ingin } \\
\text { bersaing. }\end{array}$ & \\
\hline 3 & $\begin{array}{l}\text { Yi yan chu kou si ma } \\
\text { nan zhui }\end{array}$ & $\begin{array}{l}\text { Kata yang telah terucap tak dapat ditarik } \\
\text { kembali walau ditarik dengan menggunakan } \\
\text { tenaga empat ekor kuda sekalipun. }\end{array}$ & \\
\hline 4 & $\begin{array}{l}\text { Bu fei ze yi yi fei } \\
\text { chong tian bu ming ze } \\
\text { yi yi ming jing ren }\end{array}$ & $\begin{array}{l}\text { Burung itu mungkin belum bisa terbang, } \\
\text { tetapi begitu bisa terbang, ia akan melejit ke } \\
\text { angkasa. Ia belum bisa menangis, tetapi } \\
\text { begitu menangis, semua orang akan terkejut } \\
\text { mendengarnya. }\end{array}$ & \\
\hline 5 & $\begin{array}{l}\text { San ren xing bi you } \\
\text { wo shi yan ze qi shan } \\
\text { zhe er cong zhi qi bu } \\
\text { shan zhe er gai zhi }\end{array}$ & $\begin{array}{l}\text { Pada saat aku berjalan berdampingan } \\
\text { dengan dua orang lain, mereka bisa } \\
\text { kuanggap sebagai guruku. Hal-hal baik } \\
\text { mereka akan kuambil dan kutiru, sementara } \\
\text { hal-hal buruk mereka akan kujauhi. }\end{array}$ & \\
\hline 6 & $\begin{array}{l}\text { Di zi bu bi bur u shi } \\
\text { shi bu bi xian yu di zi }\end{array}$ & $\begin{array}{l}\text { Murid tidak selalu berarti lebih rendah dari } \\
\text { gurunya, atau guru tidak selalu berarti lebih } \\
\text { pintar dari muridnya. }\end{array}$ & \\
\hline 7 & $\begin{array}{l}\text { Er ren tong xin qi li } \\
\text { duan jin tong xin zhi } \\
\text { yan qi xiu ru lan }\end{array}$ & $\begin{array}{l}\text { Buah pikiran dari dua orang akan member } \\
\text { kekuatan sehingga mampu memotong emas. } \\
\text { Kata-kata yang berasal hati yang bersatu } \\
\text { akan terlontar wangi seperti harumnya } \\
\text { bunga anggrek. }\end{array}$ & $\begin{array}{l}\text { Etika berumah } \\
\text { tangga dan } \\
\text { bermasyarakat }\end{array}$ \\
\hline 8 & $\begin{array}{l}\text { Fu mu zhi xin ren jie } \\
\text { you zhi }\end{array}$ & $\begin{array}{l}\text { Tidak ada orang tua yang tidak mencintai } \\
\text { anak-anak mereka. }\end{array}$ & \\
\hline
\end{tabular}




\begin{tabular}{|c|c|c|c|}
\hline 9 & $\begin{array}{l}\text { Ai ren zhe ren bi cong } \\
\text { er ai zhi li ren zhe ren } \\
\text { bi cong er li zhi wu } \\
\text { ren zhe ren bi cong er } \\
\text { wu zhi hai ren zhe ren } \\
\text { bi cong er hai zhi }\end{array}$ & $\begin{array}{l}\text { Siapa pun yang mencintai orang lain akan } \\
\text { dicintai oleh orang lain, siapapun yang } \\
\text { memanfaatkan orang lain akan } \\
\text { dimanfaatkan juga oleh orang lain. Siapa } \\
\text { pun yang membenci orang lain akan dibenci } \\
\text { oleh orang lain, siapa pun yang melukai } \\
\text { orang lain akan dilukai oleh orang lain lagi. }\end{array}$ & \\
\hline 10 & $\begin{array}{l}\text { Fu ci er jiao zi xiao er } \\
\text { zhen xiong ai er you di } \\
\text { jing er shun }\end{array}$ & $\begin{array}{l}\text { Sang ayah adalah seorang yang sopan dan } \\
\text { mendidik anak-anaknya dengan benar, } \\
\text { putranya adalah orang yang bersifat sama } \\
\text { dan menasehati orang-orang yang lebih tua } \\
\text { darinya dengan benar, sang kakak menjaga } \\
\text { dan berteman dengan adiknya yang } \\
\text { menghormati dan mematuhi kakaknya. }\end{array}$ & \\
\hline 11 & $\begin{array}{l}\text { Zhi zhe qian lu bi you } \\
\text { yi shi yu zhe qian lu bi } \\
\text { you yi }\end{array}$ & $\begin{array}{l}\text { Orang bijak dapat berpikir seribu kali, } \\
\text { namun masih saja bisa melakukan satu } \\
\text { kesalahan. Orang bodoh dapat berpikir } \\
\text { seribu kali, namun paling tidak ia bisa } \\
\text { melakukan satu hal dengan benar. }\end{array}$ & $\begin{array}{c}\text { Etika } \\
\text { kepemimpinan }\end{array}$ \\
\hline 12 & $\begin{array}{l}\text { Yi ren rei sheng xian ji } \\
\text { ji quan }\end{array}$ & $\begin{array}{l}\text { Jika seseorang mencapai titik tertingginya, } \\
\text { bahkan binatang peliharaannya pun akan } \\
\text { turut naik ke surga. }\end{array}$ & \\
\hline
\end{tabular}

